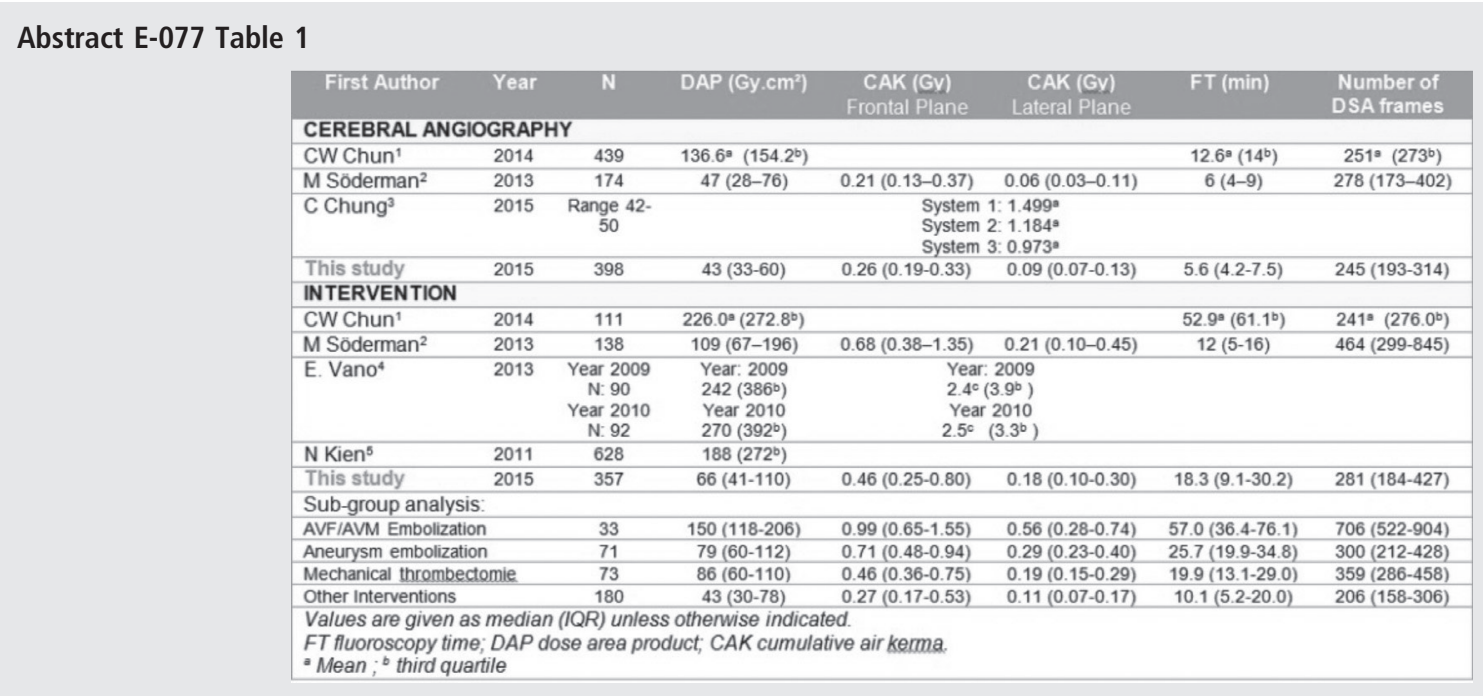

Disclosures A. Hassan: 2; C; GE Healthcare. S. Amelot: 5; C; GE Healthcare.

\section{E-078 ENDOVASCULAR VEIN APPROACH AND DIRECT PUNCTURE RETROGRADE VEIN APPROACH FOR CURATIVE AVM TREATMENT: A NEW UNREPORTED TECHNIQUE}

W Yakes. Vascular Malformation Center, Englewood, CO

\subsection{6/neurintsurg-2016-012589.150}

Purpose To evaluate the role of Retrograde Vein and Direct Puncture Retrograde Vein Endovascular Repair of Large Peripheral AVMs.

Materials and methods Eighty-seven patients (45 males, 42 females; age: 14-72, mean age: 27 years) presented for repair of AVMs involving head and neck, shoulder, chest wall, intrathoracic, abdominal, renal, pelvic, buttock, and extremities. Ethanol and ethanol/coils were the embolic agents used. Retrograde transvenous catheterizations and vein direct puncture retrograde vein approaches were used in all patients.

Results Eighty-five of 87 patients are cured at long-term follow-up (f/up: 14 months to 138 months; mean: 42 months) and 2 patients' therapy is on-going. Complications include 1 pelvic AVM post-Rx small bleed not requiring transfusion; 1 pelvic AVM coils eroded into bladder wall removed uneventfully via trans-urethra endoscopy; 2 infections treated with antibiotics; 2 patients' coils superficially eroded and uneventfully removed; and 1 patient subcutaneous hematoma removed (7/87 patients; 8\% minor complications).

Conclusions Retrograde vein and direct puncture vein access and embolization of AVMs in many anatomic locations have proven curative at long-term f/up of AVMs in multiple anatomic locations with a low complication rate. Reproducible and consistent results of this technique have been reported by Yakes (1990) et al, Jackson (1996) et al and Cho (2008), et al.

Disclosures W. Yakes: None.

\section{E-079 ANGIOGRAPHIC ANATOMICAL FEATURES FOR TRANSBRACHIAL CAROTID CANNULATION OF A BALLOON-GUIDE CATHETER}

T Mori, S Kasakura, T Iwata, Y Tanno, K Yoshioka. Stroke Treatment, Shonan Kamakura General Hospital Stroke Center, Kamakura, Japan

\subsection{6/neurintsurg-2016-012589.151}

Background and purpose Transfemoral approach has been a common technique for advancing a balloon-guide catheter (BGC) for emergency clots removal therapy in acute stroke patients. When aortic or peripheral arterial conditions limit transfemoral access, transbrachial approach is attempted as the alternative. The purpose of our study was to investigate anatomical features of the aortic arch (AA) for transbrachial carotid cannulation (TCC) of a BGC.

Patients and methods Included were patients who underwent endovascular reperfusion therapy with transbrachial BGC between Jan 2014 and Jun 2015. Evaluated were successful cannulation of the BGC and anatomical features of the aortic arch.

Results Fourteen patients were analyzed. TCC was successful in $10(71 \%)$ of 14 lesions: 6 of 7 right carotid artery (CA) lesions and 4 of 7 CA lesions. Two left CA lesions of a bovine type AA were transbrachially cannulated, whereas only two of five left CA lesions of a non-bovine AA were cannulated and their angle (BC-ltCA) between the brachiocephalic artery and the left CA was 20 degree or more. However, three lesions with BC-ltCA angle of less than 20 degree were not cannulated. Six right CA lesions with the angle (SA-rtCA) between the right subclavian artery and the right CA of 30 degree or more were cannulated; however one lesion with SA-rtCA angle of less than 30 degree was not.

Conclusion A BGC can be transbrachially cannulated to the $\mathrm{CA}$ in patients with the left $\mathrm{CA}$ of a bovine $\mathrm{AA}$, the left $\mathrm{CA}$ of a non-bovine AA with the BC-ltCA angle of 20 degree or more or the right $\mathrm{CA}$ with the SA-rtCA angle of 30 degree or more.

Disclosures T. Mori: None. S. Kasakura: None. T. Iwata: None. Y. Tanno: None. K. Yoshioka: None. 